\title{
СОЦИАЛЬНАЯ ДИСТАНЦИЯ, ХАРАКТЕРНАЯ ДЛЯ МУСУЛЬМАН-МИГРАНТОВ ПО ОТНОШЕНИЮ К ПРЕДСТАВИТЕЛЯМ ПРИНИМАЮЩЕЙ СТОРОНЫ РЕГИОНА НИЖНЕГО ПОВОЛЖЬЯ 1
}

\section{SOCIAL DISTANCE CHARACTERISTIC OF MUSLIM MIGRANTS IN RELATION TO THE REPRESENTATIVES OF THE RECEIVING SIDE OF THE LOWER VOLGA REGION}

A. Chernov

Summary: The contradiction between the desire to preserve ethnic and group identity and the need to comply with the economic, social, psychological standards existing in the host society leads to the formation and maintenance of social distance boundaries among migrants. Social distance reflects the gradations and degrees of understanding of closeness and mutual understanding that characterize social and personal relationships. Then social distance is determined by the degree of closeness between groups and individuals, and it measures the influence that groups and individuals have on each other. From a functional point of view, they are perceived by them as a means of optimizing interpersonal interactions, maintaining adherence to traditional values, adaptive manifestation of psychological and socio-psychological properties of a person. At the same time, it is the stylistic features of interaction, value orientations and elements of self-esteem that determine the nature of the boundaries of the social distance in migrants: "optimal", "narrowed", "extended". Being universal, this influence is specifically manifested in different groups of migrants. In the group of labor migrants, it determines the vector towards narrowing the boundaries of the social distance, in the group of migrant students - towards expansion and optimization. In terms of content the difference in the direction of the vectors in the first case can be described as an orientation towards preserving ethnic identity, and in the second, as a search for ways to ensure a tolerant attitude from the "native" people, to become "our own" in the context of the host community. From the point of view of the mechanism of influence, the stylistic features of interaction, value orientations and elements of selfassessment predetermine the differences in the orientation towards the social (labor migrants) and personal (migrants students) focus of the adaptation process. In general, it can be concluded that the boundaries of the social distance of migrants are a manifestation of the characteristics of their self-awareness.

Keywords: migrants, social distance, boundaries of social distance, optimal boundaries of social distance, expanded boundaries of social distance, narrowed boundaries of social distance, social focus, personal focus.

\author{
Чернов Александр Юрьевич \\ Д.псх.н., дочент, с.н.с., Волгоградский \\ государственный университет; профессор, \\ РАНХГИС (Волгоградский филиал) \\ achernov1@yandex.ru
}

Аннотация: Противоречие между стремлением сохранить этническую и групповую идентичность и необходимостью соответствовать существующим в принимающем обществе экономическим, социальным, психологическим стандартам приводит к формированию и поддержанию у мигрантов границ социальной дистанции. Социальная дистанция отражает градации и степени понимания близости и взаимопонимания, которые характеризуют социальные и личностные отношения. Тогда социальная дистанция определяется степенью близости между группами и индивидами, и ей измеряется влияние, которое группы и индивиды оказывают друг на друга. С функциональной точки зрения они воспринимаются ими как средство оптимизации межперсональных взаимодействий, удержания приверженности традиционным ценностям, адаптивного проявления психологических и социальнопсихологических свойств личности. При этом именно стилевые особенности взаимодействия, ценностные ориентации и элементы самооценки детерминируют характер границ социальной дистанции у мигрантов: «оптимальный», «суженный», «расширенный». Являясь универсальным, это влияние специфически проявляется в разных группах мигрантов. В группе трудовых мигрантов оно детерминирует вектор к сужению границ социальной дистанции, в группе мигрантов-учащихся - к их расширению и оптимизации. Содержательно различие в направленности векторов в первом случае можно описать как установку на сохранение этнической идентичности, а во втором, как поиск способов обеспечить себе толерантное отношение со стороны окружающих людей, стать «своим» в контексте принимающего сообщества. С точки зрения механизма воздействия стилевые особенности взаимодействия, ценностные ориентации и элементы самооценки предопределяют различия в ориентации на социальный (трудовые мигранты) и личностный фокус процесса адаптации. В целом можно сделать заключение о том, что границы социальной дистанции мигрантов являются проявлением особенностей их самосознания.

Ключевые слова: мигранты, социальная дистанция, границы социальной дистанции, оптимальные границы социальной дистанции, расширенные границы социальной дистанции, суженные границы социальной дистанции, социальный фокус, личностный фокус. 


\section{Введение}

Л юди, составляющие социальную группу «мигранты», имеют характерные для них особенности стиля жизни и социальных установок, специфические черты отношений и взаимодействия. Такое своеобразие сказывается на том, как мигранты выстраивают свое социальное поведение в контексте задачи адаптации к новым для них социально-культурным обстоятельствам. Неизбежно возникает противоречие между стремлением сохранить этническую и групповую идентичность и необходимостью соответствовать существующим в принимающем обществе экономическим, социальным, психологическим стандартам. Психологическое содержание названного противоречия неоднократно становилось предметом теоретических и эмпирических исследований $[2 ; 3 ; 4 ; 12 ; 17 ; 19]$.

С нашей точки зрения, особого внимания требует эффект медиации межличностного взаимодействия, приверженности системе ценностей, выраженности различных аспектов самооценки как компонента самосознания мигрантов социальной дистанцией. В немногочисленных исследованиях, посвященных роли социальной дистанции в контексте межкультурной коммуникации рассматривалась ее взаимосвязь с позитивными и негативными установками по отношению к миграции. Вместе с тем, вопрос о том, как социальная дистанция маркируется самими мигрантами, и какую роль она при этом играет в разрешении названного выше противоречия, пока остается без ответа.

Методологической и теоретической основой исследования являются представления о феномене социальной дистанции в современной социальной психологии $[1 ; 5 ; 6]$.

Трактовки сущности и функций социальной дистанции весьма разнообразны. С одной стороны, считается, что социальная дистанция характеризует социальные взаимодействия в физическом пространстве. Однако, с другой стороны, этому понятию придается и метафорический смысл: дистанции, которые разделяют людей, существуют не только в «пространстве», но и «психологически». В этом случае социальная дистанция отражает градации и степени понимания близости и взаимопонимания, которые характеризуют социальные и личностные отношения. Тогда социальная дистанция определяется степенью близости между группами и индивидами, и ей измеряется влияние, которое группы и индивиды оказывают друг на друга.

Социальная дистанция выполняет специфические функции в отношениях между социальными группами. Она поддерживает различия между ними, устанавливает уровень групповой идентичности, позволяет сохранять групповое единство. Как социально-психологический феномен дистанция конструируется людьми, заинтересованными в сохранении этнического своеобразия, особенно если его носители живут в тесном соседстве друг с другом в пространственном смысле. Вначале дистанцирование проявляется в действиях, которые направлены на избегание прямого общения. Позднее эти действия перестают предполагать обязательное пространственное отдаление.

Важно подчеркнуть, что в ходе межгруппового взаимодействия постепенно складывается «нормальная дистанция», соблюдаемая людьми, общающимися друг с другом. В этом случае целесообразно говорить о психологической дистанции как о частном случае социальной дистанции. Психологическая дистанция проявляется в деятельности, в отношениях, в коммуникациях двух или нескольких индивидов или больших сообществ, предполагающей наличие многоуровневой системы связей, детерминированных социальными и психологическими факторами. Важно подчеркнуть, что осознание человеком психологической дистанции связано с компонентами его самосознания, прежде всего с самооценкой и системой ценностей [14].

Мигранты представляют собой социальную группу, имеющую специфическую этническую идентичность. Качественные и количественные признаки формирующейся у них социальной дистанции опосредованы привнесенными в новую для них культурную и социальную среду традициями, а также опытом пережитых межнациональных контактов. В этой логике закономерным выглядит предположение, согласно которому не только отдельные индивиды обладают чувством дистанции по отношению к людям, с которыми вступают в контакт. Такое же чувство дистанции проявляется и в контексте отношений социальных групп. Члены социальной группы осознают для себя социальную дистанцию, которая разделяет их с другой социальной группой, что, в свою очередь, модифицирует и межперсональные взаимодействия, затрудняя взаимопонимание. К идентичным последствиям приводит, с нашей точки зрения и религиозная (точнее, в данном случае, «духовная») идентичность, что позволяет обратиться к мигрантам - представителям исламской культуры, как эмпирическому объекту исследования.

Таким образом, предметом нашего исследования выступает социальная дистанция, характерная для мусульман-мигрантов по отношению к представителям принимающей стороны региона Нижнего Поволжья. В исследовании учитывалась неоднородность социальной группы «мигранты». В.В. Константинов описывает три типа миграции: «временную», «постоянную», «космополитическую». Мы обращаемся к одному из этих типов - «временной» миграции, дифференцируя внутри 
этого типа «трудовую» и «учебную» миграцию. В первом случае речь идет о мигрантах - сезонных рабочих, во втором - об учащихся высших учебных заведений. Предполагается, что социальная дистанция обеих групп имеет специфические проявления. Целью исследования является выявление внутренней согласованности социальной дистанции названных групп мигрантов с особенностями проявления межличностного взаимодействия и компонентами их самосознания - системой ценностей и самооценкой.

\section{Meто $\Delta$}

Для измерения значений социальной дистанции чаще всего употребляется шкала, разработанная Э. Богардусом. Обращаясь к истории создания соответствующего инструмента, В.К. Сергеев приводит ее оригинальный вариант. В соответствии с ним респондентам предлагалось ответить на вопрос, в каком качестве они готовы принять представителей другой национальности: 1. Как близких родственников посредством брака; 2. Как близких знакомых по проведению досуга; 3. Как соседей по улице; 4. Как работающих по моей профессии в моей стране; 5. Как жителей моей страны; 6. Как гостей в моей стране; 7. Должны быть исключены из моей страны [9].

Шкала Э. Богардуса неоднократно модифицировалась с целью достижения более точной оценки социальной дистанции и расширения возможностей интерпретации результатов. Например, Л.Г. Почебут и Д.С. Безносов предложили использовать биполярную шкалу вместо традиционной ранговой и ввели коэффициенты социальной дистанции, этнической толерантности и этнической идентичности. [8]. Н.В. Панина и Е.И. Головаха, сохраняя ранговую шкалу, предлагают рассчитывать индекс национальной дистанцированности - средний балл по семибалльной шкале социальной дистанции. В этом случае можно говорить о том, что дистанция может быть минимальной, или максимальной, или находиться между этими значениями. [7].

Типичная инструкция к шкале Э. Богардуса предполагает оценку респондентами одной социальной группы представителей другой социальной группы. В соответствии с целями нашего исследования инструкция была изменена так, чтобы выяснить, как представители изучаемой группы мигрантов оценивают свою социальную дистанцию по отношению к представителям социума, в котором они оказались. Соответственно, модификации подверглась и формулировка типов социальных отношений. В итоге респондентам предлагалась следующая версия шкалы измерения социальной дистанции.

Инструкция: Оцените, как, по Вашему мнению, воспринимают Вас люди - коренные жители того региона, в который Вы приехали для работы или учебы. Выберите только один критерий из предложенных ниже.

1. Воспринимают меня как родственника посредством брака.

2. Воспринимают меня как друга.

3. Воспринимают меня как соседа, живущего в том же доме или в доме рядом.

4. Воспринимают меня как человека, занимающегося тем же видом деятельности.

5. Воспринимают меня как не гражданина страны, в которую я приехал работать или учиться.

6. Воспринимают меня как человека, случайно оказавшегося рядом.

7. Воспринимают меня как человека, которого предпочли бы не видеть в своей стране.

Для оценки социальной дистанции использовалась ранговая шкала. Результаты фиксировались как границы, которые респонденты устанавливают для себя при взаимодействии с представителями принимающего социума: «расширенные» границы (1-3 балла), «оптимальные границы» (4-5 баллов), «суженные» границы (6-7 баллов).

Для диагностики особенностей межличностного взаимодействия применялась методика В. Шутца, адаптированная А.А. Руковишниковым [11]. Инструмент сфокусирован на измерении поведенческих проявлений в трех областях межличностных отношений: «Включенность» - интенсивность контактов, «Контроль» - степень зависимости, «Эмоции» - степень готовности делиться чувствами. Инструментом изучения свойств самосознания личности стала методика «Личностный дифференциал», характеризующая полюса 3-х классических факторов семантического дифференциала: «оценки», «силы», «активности» [10]. Ценностные ориентации изучались на основе методики Ш. Шварца, согласно которому базовые ценности расположены в пространстве двух измерений: «открытость изменениям - консерватизм» и «самовозвышение - самотрансцедентность». При этом «открытость изменениям» и «самотрансцедентность» соответствуют «личностному» фокусу, а «конверватизм и самовозвышение» - социальному фокусу. [13].

В исследовании приняли участие 128 респондентов 65 трудовых мигрантов из стран Средней Азии и 63 учащихся высших и средних учебных заведений из стран Средней Азии, Казахстана и Азербайджана.

\section{Результаты и интерпреташия}

В Таблице 1 представлены результаты описательной статистики данных, полученных при измерении социальной дистанции в социальных группах «трудовые мигранты» и «мигранты-учащиеся». 
Таблица 1.

Результаты описательной статистики переменной «социальная дистанция»

\begin{tabular}{|l|c|c|c|}
\hline Социальная группа & N & Среднее значение & $\begin{array}{l}\text { Стандартное } \\
\text { отклонение }\end{array}$ \\
\hline Трудовые мигранты & 65 & 5,4 & 1,19 \\
\hline Мигранты учащиеся & 63 & 3.8 & 2,12 \\
\hline
\end{tabular}

Примечание. Проверка на нормальность распределения (тест Колмогорова-Смирнова) p>0,05

Применение t-критерия Стьюдента указывает на статистически достоверные различия между средними значениями переменной в исследуемых группах ( $T=3,289$, $\mathrm{p}<0,05)$. Следовательно, дальнейший анализ целесообразно проводить отдельно для каждой из групп респондентов.

Далее для каждой из групп респондентов проводился кластерный анализ с целью установить содержательные характеристики дисперсии полученных результатов и на этой основе определить границы социальной дистанции - «расширенные», «оптимальные», «суженные». В Таблице 2 представлены результаты кластерного анализа переменной «социальная дистанция» для социальной группы «трудовые мигранты».

Первый кластер соответствует «оптимальным» границам социальной дистанции (60\% респондентов), 2 кластер - «расширенным» границам (20\% респондентов), третий кластер - «суженным границам» (20\% респондентов).
В Таблице 3 представлены результаты кластерного анализа переменной «социальная дистанция» для социальной группы «мигранты-учащиеся».

Первый кластер соответствует «оптимальным» границам социальной дистанции (32\% респондентов), 2 кластер - «расширенным» границам (40\% респондентов), третий кластер - «суженным границам» (38\% респондентов).

Полученные результаты позволяют определить векторы конструирования и восприятия границ социальной дистанции. В исследуемых группах мигрантов эти векторы разнонаправленные. В группе трудовых мигрантов конечные центры кластеров «сдвинуты» в сторону сужения границ социальной дистанции. Условно этот вектор можно назвать «оптимально-суженным». Его содержание можно описать как тенденцию к обособлению от людей другой культуры, стремление скрывать проблемы и личностные особенности, прибегать к психологическим защитам в ходе межличностного взаимодействия. Здесь же можно упомянуть установку на сохранение этнической идентичности и, в некоторых случаях, даже ксенофобные установки, проявляющиеся в данном случае как опасения, что окружающие люди воспринимают мигранта как «совершенно чужого». Вместе с тем, имеющиеся оптимальные границы восприятия социальной дистанции у трудовых мигрантов оставляют возможность оптимальной адаптации.

Вектор установления и восприятия границ социальной дистанции у мигрантов-учащихся направлен в другую сторону. Здесь есть тенденция к расширению

Таблица 2.

Результаты кластерного анализа переменной «социальная дистанция» для трудовых мигрантов

\begin{tabular}{|c|c|c|c|}
\hline \multirow[b]{2}{*}{$\begin{array}{c}\text { Переменная } \\
\text { «социальная дистанция» }\end{array}$} & \multicolumn{3}{|c|}{ Кластеры } \\
\hline & $\begin{array}{c}1 \\
\text { Оптимальные границы социальной } \\
\text { дистанции }\end{array}$ & $\begin{array}{c}2 \\
\text { Расширенные границы социальной } \\
\text { дистанции }\end{array}$ & $\begin{array}{c}3 \\
\text { Суженные границы социальной } \\
\text { дистанции }\end{array}$ \\
\hline Конечные центры кластеров & 5,47 & 3,60 & 6,99 \\
\hline Процент респондентов в кластере & $60 \%$ & $20 \%$ & $20 \%$ \\
\hline N & 65 & & \\
\hline
\end{tabular}

Таблица 3.

Результаты кластерного анализа переменной «социальная дистанция» для мигрантов-учащихся

\begin{tabular}{|c|c|c|c|}
\hline \multirow[b]{2}{*}{$\begin{array}{c}\text { Переменная } \\
\text { «социальная дистанция» }\end{array}$} & \multicolumn{3}{|c|}{ Кластеры } \\
\hline & $\begin{array}{c}1 \\
\text { Оптимальные границы социальной } \\
\text { дистанции }\end{array}$ & $\begin{array}{c}2 \\
\text { Расширенные границы социальной } \\
\text { дистанции }\end{array}$ & $\begin{array}{c}3 \\
\text { Суженные границы социальной } \\
\text { дистанции }\end{array}$ \\
\hline Конечные центры кластеров & 4,00 & 1,70 & 6,57 \\
\hline Процент респондентов в кластере & $32 \%$ & $40 \%$ & $28 \%$ \\
\hline $\mathrm{N}$ & 63 & & \\
\hline
\end{tabular}


границ, и этот вектор обозначается как «оптимальнорасширенный». Он характеризуется наличием противоречия между стремлением сохранить установки на сохранение национальной идентичности посредством демонстрации обособленности и изолированности, и поиском способов обеспечить себе толерантное отношение со стороны окружающих людей, стать «своим».

Выявленные различия можно объяснить с разных позиций. Они могут быть следствием специфики аккультурационных процессов, в частности восприятием черт новых культурных и социальных обстоятельств, особенностями взаимодействия с непосредственным социальным окружением, типично выбираемыми стратегиями совладания с отрицательным воздействием социального контекста и т.д. [15; 16; 18].

С нашей точки зрения правомерна гипотеза о влиянии на конструирование и восприятие мигрантами присущих им особенностей осуществления межличностного взаимодействия и системы ценностей. Для ее проверки был проведен регрессионный анализ, где в качестве за- висимой переменной использовались показатели социальной дистанции в разных группах мигрантов с учетом их принадлежности к выявленным кластерам, а в качестве независимых переменных данные, полученные в результате предъявления респондентам методик ОМО, личностный дифференциал и тест ценностей Ш. Шварца. Обобщенные результаты приведены в Таблице 4.

Результаты регрессионного анализа позволяют предсказывать значение переменной «социальная дистанция» и, следовательно, рассматривать независимые переменные как факторы, детерминирующие ее психологическое содержание. Следовательно, появляется возможность судить о присущих разным группам мигрантов психологических и социально-психологических свойствах, специфически определяющих социальную дистанцию в отношении людей принимающего общества. Например, в группе «трудовые мигранты» с оптимальными границами социальной дистанции в межличностных отношениях с очень маленькой долей вероятности можно ожидать создания и сохранения удовлетворительных отношений с людьми с опорой на

Результаты регрессионного анализа. ${ }^{1}$

Таблица 4.

\begin{tabular}{|c|c|c|c|c|c|c|}
\hline & \multicolumn{3}{|c|}{ Трудовые мигранты } & \multicolumn{3}{|c|}{ Мигранты-учащиеся } \\
\hline & \multicolumn{6}{|c|}{ Коэффициенты регрессии } \\
\hline & 1 & 2 & 3 & 1 & 2 & 3 \\
\hline Включенность & & & $\beta=2,140^{*}$ & & $\beta=3.476^{*}$ & \\
\hline Контроль & $\beta=-1,486^{* *}$ & & & $\beta=-4.203^{*}$ & & $\beta=2,012^{*}$ \\
\hline Аффект & & $\beta=1,476^{*}$ & & $\beta=2,120^{*}$ & & \\
\hline Оценка & & & & $\beta=3,700^{*}$ & & $\beta=-1,846^{*}$ \\
\hline Сила & & & $\beta=3,128^{*}$ & & & $\beta=-2,294^{*}$ \\
\hline \multicolumn{7}{|l|}{ Активность } \\
\hline \multicolumn{7}{|l|}{ Гедонизм } \\
\hline \multicolumn{7}{|l|}{ Доброта } \\
\hline Традиции & & $\beta=3.946^{*}$ & $\beta=2,113^{* *}$ & & & $\beta=3,394^{*}$ \\
\hline Самостоятельность & & & $\beta=-1,175^{*}$ & & & $\beta=1,927^{*}$ \\
\hline Стимуляция & & & & & $\beta=2,121^{* *}$ & \\
\hline Конформность & $\beta=3,735^{* *}$ & & & & $\beta=2,183^{* *}$ & \\
\hline \multicolumn{7}{|l|}{ Универсализм } \\
\hline Достижения & & & $\beta=-2,835^{*}$ & $\beta=2,746^{* *}$ & & \\
\hline Власть & & & & & & \\
\hline
\end{tabular}

Составлено автором

Примечания:

1 Зависимая переменная - социальная дистанция.

1 - оптимальные границы социальной дистанции

2- расширенные границы социальной дистанции

3 - суженные границы социальной дистанции

${ }^{*} p<, 01$

$* * p<, 005$ 
контроль и силу («контроль» - $\beta=-1,486^{* *}$ ). В тоже время проявлена тенденция, сдерживать склонности, имеющие негативные социальные последствия: послушание, самодисциплина, вежливость, уважение родителей и старших («традиции» $\beta=3,735^{* *}$ ). Психологические и социально-психологические свойства мигрантов-студентов с оптимальными границами социальной дистанции концентрируются вокруг ценности достижения личного успеха, социального одобрения («достижения» $\left.\beta=2,746^{* *}\right)$, отсутствия стремления доминировать в межличностных отношениях («контроль» $\beta=-4,203^{*}$ ), тенденции устанавливать достаточно близкие отношения с окружающими людьми («аффект» $\beta=2,120 *$ ), склонности осознавать себя носителем позитивных, социально желательных характеристик, в определенном смысле удовлетворен собой («оценка» $\beta=3,700^{*}$ ). Подобные описания можно делать и в отношении респондентов, относящихся к разным группам мигрантов с различной выраженностью границ социальной дистанции, исходя из данных, содержащихся в Таблице 4.

Важнее сформулировать обобщения более высокого порядка.

Во-первых, следует сделать заключение об универсальности влияния психологических и социально-психологических свойств личности на конструирование и восприятие мигрантами границ социальной дистанции. Это влияние проявляется как в отношении трудовых мигрантов, так и в отношении мигрантов-студентов. Оно имеет специфический характер для разных типов границ социальной дистанции. Наибольшее влияние свойства личности мигрантов оказывают на «сужение» границ социальной дистанции. В группе «мигранты-учащиеся» психологические и социально-психологические свойства оказывают влияние и на оптимальные границы социальной дистанции.

Во-вторых, в разных группах мигрантов влияние психологических и социально-психологических свойств проявляется по-разному. Так, свойство «включенность» в группе «трудовые мигранты» предопределяет размер суженных границ социальной дистанции, а в группе «мигранты-учащиеся» - расширенных границ. Ценность «комформность» у трудовых мигрантов способствует установлению оптимальных, а у студентов-мигрантов расширенных границ. Скорее всего, эти различия объясняются возрастом респондентов, особенностями стиля жизни, выбором стратегий совладания.

В-третьих, целесообразно прокомментировать результаты, полученные при применении методики ценностей Ш. Шварца. Согласно его теории, ценности интерпретируются с точки зрения целей и мотивов личности, то есть раскрывают особенности ее самосо- знания. С этой точки зрения можно судить о различиях этих особенностей в исследованных группах мигрантов. В группе мигрантов-учащихся на конструирование и поддержание границ социальной дистанции оказывают влияние ценности стимуляции, достижений, самостоятельности. Все они, по Ш. Шварцу, являются выражением «личностного фокуса» ценностей и выражают стремление к открытости изменениям и самоутверждению. С другой стороны, мигранты-учащиеся конструируют границы социальной дистанции, ориентируясь на ценности конформизма и традиций. Эти ценности относятся к «социальному фокусу» и выражают стремление к использованию защитных механизмов в копинге. Таким образом, можно предполагать наличие особенностей самосознания, способствующих возникновению тенденций, предполагающих вероятность внутриличностного конфликта: действие механизмов психологической защиты препятствует самореализации. С нашей точки зрения такой конфликт не проявляется в группе трудовых мигрантов. Здесь ценности «традиции» и «конформизм» способствуют оптимизации и расширению границ социальной дистанции, а низкие значения ценностей «самостоятельность» и «достижения» ведут к их сужению. В целом ценности трудовых мигрантов тяготеют к «социальному фокусу».

\section{Выводы}

1. Маркировка мигрантами границ социальной дистанции с представителями принимающего социума выполняет ряд функций. Они состоят в оптимизации межперсональных взаимодействий, удержанию приверженности традиционным ценностям, адаптивному проявлению психологических и социально-психологических свойств личности. Конструирование и восприятие границ социальной дистанции специфично для разных групп мигрантов (трудовых мигрантов и мигрантов-учащихся). Специфика проявляется как тенденция к сужению границ в случае трудовых мигрантов и их расширению у мигрантов-учащихся.

2. Психологическое содержание социальной дистанции детерминируется сочетанием выраженности компонентов самооценки и ценностных ориентаций. Это позволяет сделать заключение о важной роли различных аспектов самосознания в определении личностью границ социальной дистанции. Роль самосознания универсальна как в группе трудовых мигрантов, так и в группе мигрантов учащихся.

3. Механизм конструирования границ социальной дистанции действует как ориентация на социальный или личностный фокус, что связано с реализацией установок в процессе межличностного взаимодействия. 


\section{ЛИТЕРАТУРА}

1. Духновский С.В., Куликов Л.В. Социально-психологическая дистанция в межличностных отношениях: Факторы и регуляция//Вестник СанктПетербургского университета. - Сер. 12. - 2009. - Вып. 2 - Ч.І. - С. 20 -26.

2. Егизарянц А.А. Адаптация мигрантов как проблема исследования психологии аккультурации \Вестник университета Российской академии образования. - 2010. - № 1. - C. 103-105.

3. Елизаров С.Г. Включенность субъекта в социальную среду: основные направления исследований в зарубежной и отечественной психологии І Педагогическое образование в России।|2918. - № 11. - С. 124-130.

4. Завьялов А.А. Социальная адаптация мигрантов: социологический анализ теории и практики. Монография. - Иркутск, 2019. - 264 с.

5. Кроник А. А., Кроник Е.А. Психология человеческих отношений. - Дубна: Издательский центр «Феникс», Изд- во «Когито- центр», 1998. - 224 с.

6. упрейченко А.Б. Восприятие психологической дистанции различными социальными группами. - Ежегодник Российского психологического общества: Материалы III Всероссийского съезда психологов. 25-28 июня 2003 года: В 8 т. - Т. 4. - СПб.: Изд- во СПбГУ, 2003. - С. 565-567.

7. Панина Н.В., Головаха Е.И. Национальная толерантность и идентичность в Украине: опыт применения шкалы социальной дистанции в мониторинговом социологическом исследовании \ Социологический журнал. - 2006. - № 3/4. - С. 102-126.

8. Почебут Л.Г., Безносов Д.С. Психология восприятия социальной дистанции в отношении разных стран: взгляд из России // Вестник Российского университета дружбы народов. Серия: Международные отношения. - 2018. - Т. 18. - № 1.- С. 66-84. D0I: 10.22363/2313-0660-2018-18-1-66-84.

9. Сергеев В. Социальная дистанция и национальные установкиІТелескоп: журнал социологии и маркетинговых исследований. - 2008. - № 2. - С. 57-61.

10. Фетискин Н.П., Козлов В.В., Мануйлов Г.М. Социально-психологическая диагностика развития личности и малых групп. - М., 2002. - С.167-171.

11. Фетискин Н.П., Козлов В.В., Мануйлов Г.М. Социально-психологическая диагностика развития личности и малых групп. - М., 2002. - С.20-21.

12. Чжан Хэ. Методология субъектно-бытийного подхода к изучению проблемы самореализации мигрантов |Вестник университета Российской академии образования. - 2012. - №3. - С. 47-50.

13. Шварц Ш., Бутенко Т.П., Седова Д.С., Липатова А.С. Уточненная теория базовых индивидуальных ценностей: применение в России।\Психология. Журнал Высшей школы экономики. - 2012. - Т. 9 - № 1. - С. 43-70.

14. Abrams D., Hogg M., Marques J. A Social Psychological Framework for Understanding Social Inclusion and ExclusionVIn The Social Psychology of Inclusion and Exclusion/ Abrams D., Hogg M., Marques J (Ed). - Psychology Press, New York, 2005. - Pp. 1-35.

15. Amit K., Riss I. The subjective well-being of immigrants: Pre-and post-migration \I Social Indicators Research. 2014. - №, 119. - Pp. $247-264$.

16. Bornstein M.H. The specificity principle in acculturation sciencell Perspectives on Psychological Science. - № 12. - Pp. 3-45.

17. de Haas H. The internal dynamics of migration processes: A theoretical Inquiryl Journal of Ethnic and Migration Studies. - 2010. - №, 36(10). - Pp. $1587-1617$.

18. Lindert J., von Ehrenstein 0.S., Priebe, S., Mielck, A., Brähler, E. Depression and anxiety in labor migrants and refugees—a systematic review and metaanalysis।I Social Science and Medicine. - 2009. - № 69. -Pp. 246-257.

19. Massey D.S. The perils of seeing twenty-first century migration through a twentieth-century lens \ International Social Science Journal. -2019. - № 68(227-228). Pp. 101-104. 